\title{
Influence of Doping Concentration on Dielectric, Optical, and Morphological Properties of PMMA Thin Films
}

\author{
Lyly Nyl Ismail, Habibah Zulkefle, Sukreen Hana Herman, and Mohamad Rusop Mahmood \\ NANO-ElecTronic Centre, Faculty of Electrical Engineering, Universiti Teknologi MARA, 40450 Shah Alam, Malaysia \\ Correspondence should be addressed to Lyly Nyl Ismail, lyly2909@gmail.com
}

Received 20 August 2011; Revised 14 November 2011; Accepted 14 November 2011

Academic Editor: V. P. S. Awana

Copyright () 2012 Lyly Nyl Ismail et al. This is an open access article distributed under the Creative Commons Attribution License, which permits unrestricted use, distribution, and reproduction in any medium, provided the original work is properly cited.

PMMA thin films were deposited by sol gel spin coating method on ITO substrates. Toluene was used as the solvent to dissolve the PMMA powder. The PMMA concentration was varied from $30 \sim 120 \mathrm{mg}$. The dielectric properties were measured at frequency of $0 \sim 100 \mathrm{kHz}$. The dielectric permittivity was in the range of 7.3 to 7.5 which decreased as the PMMA concentration increased. The dielectric loss is in the range of $0.01 \sim-0.01$. All samples show dielectric characteristics which have dielectric loss is less than 0.05 . The optical properties for thin films were measured at room temperature across $200 \sim 1000 \mathrm{~nm}$ wavelength region. All samples are highly transparent. The energy band gaps are in the range of $3.6 \mathrm{eV}$ to $3.9 \mathrm{eV}$ when the PMMA concentration increased. The morphologies of the samples show that all samples are uniform and the surface roughness increased as the concentration increased. From this study, it is known that, the dielectric, optical, and morphology properties were influenced by the amount of PMMA concentration in the solution.

\section{Introduction}

Polymer material is widely being used in various devices as insulating material and for optoelectronic applications. This is due to their unique properties such as light weight, high flexibility, and ability to be fabricated at low temperature and low cost.

There are several organic dielectric materials that have been studied including polyvinyl phenol (PVP), polyimide, poly (methyl methacrylate) (PMMA), and other. PMMA is chosen to be dielectric materials in organic thin film transistor (OTFT) and organic field effect transistor (OFET) because it has good insulation properties such as low dielectric constant and low dielectric loss over a wide range frequency $[1,2]$. Besides, having a low dielectric permittivity and dielectric loss, the surface morphology of dielectric also determine the device performance. The surface morphology has to be smooth and uniform because it affects the electronic transport properties which depending on the grain boundaries and defect located in the film [3-5]. PMMA also has attracted high attention for optical applications. This is because it has excellent transparency [6-11].
In this work, we prepared PMMA thin films with different concentration deposited on indium tin oxide (ITO) substrate to investigate the effect on the dielectric, optical, and morphology properties of PMMA thin film.

\section{Experimental Setup}

For synthesis of the PMMA sol-gel, PMMA $\left(M_{w}=120,000\right)$ and Toluene supplied by Aldrich were used. The ITO substrate used were carefully cleaned in a acetone, followed with methanol and deionized water using ultrasonication for 10 minutes. The concentration of the PMMA in the solution was varied by varying the weight of PMMA from 30,60 , and $120 \mathrm{mg}$. The solution was stirred for 24 hours at room temperature. The PMMA thin films were deposited by spin coating method, with the speed of $3000 \mathrm{rpm}$ for $40 \mathrm{~s}$, followed by drying in a furnace at $60^{\circ} \mathrm{C}$ in atmosphere ambient for 5 minutes. After depositing the PMMA thin film, sputter coater was used to deposit $60 \mathrm{~nm}$ thick Au metal layer for metal contact. The PMMA films were characterized using impedance spectrometer to obtain the dielectric properties, 


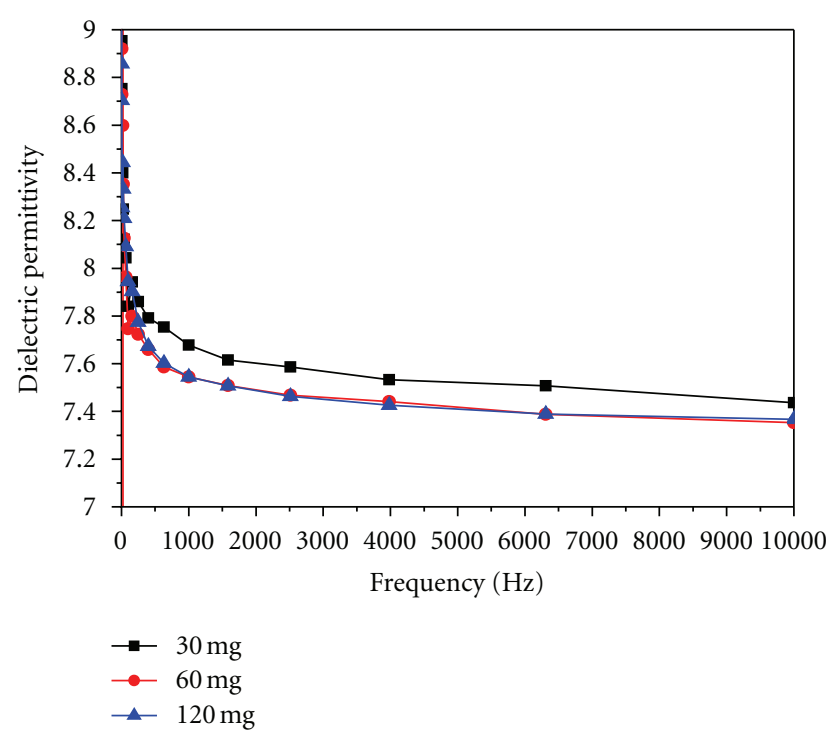

FIGURE 1: Dielectric permittivity of PMMA thin film with different concentration.

UV-VIS Spectrometer to obtain the optical properties, and atomic force microscopy (AFM) for their morphologies.

\section{Result and Discussion}

3.1. Dielectric Properties. The dielectric permittivity, $k$ of PMMA thin films are shown in Figure 1. The $k$ value is measured under the frequency from $0 \mathrm{~Hz} \sim 10 \mathrm{kHz}$. The result shows the $k$ value for all PMMA concentration reduces as the amount of PMMA concentration is increased. The lowest PMMA concentration $(30 \mathrm{mg})$ gives the highest $k$ value which is $\sim 7.5$ compared to 7.4 and 7.3 for 60 and $120 \mathrm{mg}$, respectively, at frequency of $40 \mathrm{kHz}$. This $k$ values is higher than the $k$ values obtained by other researchers which is $\sim 2.6$ at $1 \mathrm{MHz}[11,12]$. Bornand et al. have reported that $k$ value decreases when the amount of PMMA concentration is high. This is because PMMA is an amorphous material and when the concentration is increased the material becomes more firm [13]. This can be explained by the following phenomena: well conducting grains are separated by the poorly conducting grain boundaries in the material. The electron reaches the grain boundary by hopping and the resistance of grain boundary is relatively more. The electrons pile up at grain boundaries where they produce polarization. When the frequency of applied field is increased, the electrons reverse their direction of motion more often which decreases probability of electrons reaching the grain boundary and as a result polarization decreases, therefore, decreasing the dielectric constant of the developed materials with the increase in frequency [14-16].

Theoretically, a good dielectric material should have dielectric loss, $\tan \delta<0.05$ [17]. The variation of $\tan \delta$ with frequency for all PMMA concentrations is shown in Figure 2. The $\tan \delta$ was measured at frequency from $0 \mathrm{kHz} \sim$ $10 \mathrm{kHz}$. The results show that the $\tan \delta$ increased for all PMMA concentration as the frequency being increased. The

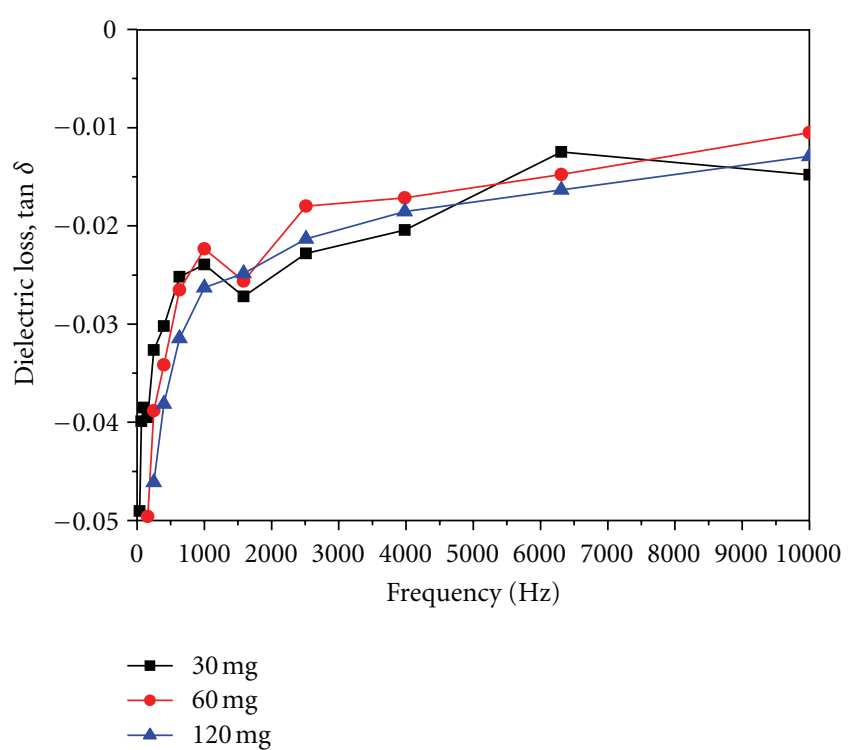

FIGURE 2: Dielectric loss of PMMA thin film with different concentration.

TABle 1: Properties of PMMA thin film at different concentration.

\begin{tabular}{lccc}
\hline $\begin{array}{l}\text { PMMA concentration } \\
(\mathrm{mg})\end{array}$ & $\begin{array}{c}\text { Thickness } \\
(\mathrm{nm})\end{array}$ & $\begin{array}{c}\text { Dielectric } \\
\text { permittivity at } \\
40 \mathrm{kHz}\end{array}$ & $\begin{array}{c}\text { Dielectric loss } \\
\text { at } 40 \mathrm{kHz}\end{array}$ \\
\hline 30 & 65.6 & 7.5 & 0.018 \\
60 & 102.7 & 7.4 & 0.015 \\
120 & 141.1 & 7.3 & -0.015 \\
\hline
\end{tabular}

increment is due to the relaxation process that causes the $\tan \delta$ to be much higher at high frequency. Other causes are due to the space charge polarization, in which, more grains in grain boundariescause the localized accumulation of charge under the influence of an electric field $[14,18]$. Table 1 summarizes the dielectric properties of PMMA thin film at different concentrations.

3.2. Optical Properties. The transmittance spectra of PMMA thin film with different concentrations were measured at the wavelength in the range of $200 \sim 1000 \mathrm{~nm}$. Figure 3 shows transmittance spectra for different PMMA concentrations. It is found that all samples are nearly transparent from the UV till NIR region. As the concentration increased the sample becomes more transparent. Therefore, it proves that all samples have the PMMA main characteristic which is highly transparent.

The optical band gap of PMMA thin film with different concentration is shown in Figure 4. The optical band gap energy $E_{g}$ can be determined using (1) where $\alpha$ is absorption coefficient, $h v$ is the incident photon energy, and $A$ is a constant. The thickness of the samples determined by surface profiler is $65.6 \mathrm{~nm}, 102.7 \mathrm{~nm}$, and $141.1 \mathrm{~nm}$ for 30,60 , and $120 \mathrm{mg}$, respectively. Figure 4 shows the intercept of tangents to the $(\alpha h v)^{2}$ versus photon energy $(h v)$ plots, estimating the values of band gap energy of 3.92 , 


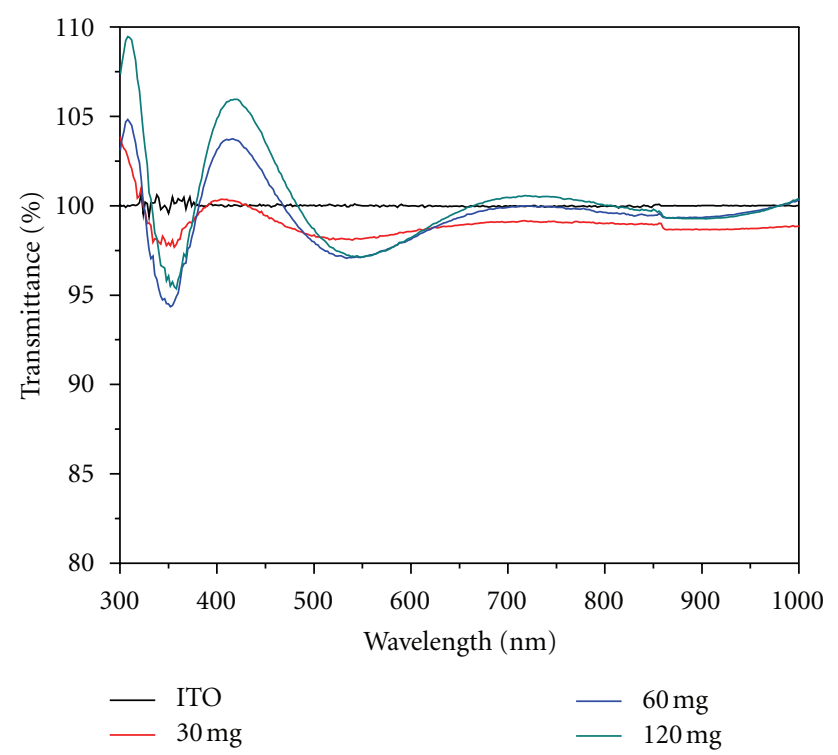

FIgURE 3: Transmittance spectrum of PMMA with different PMMA concentration.

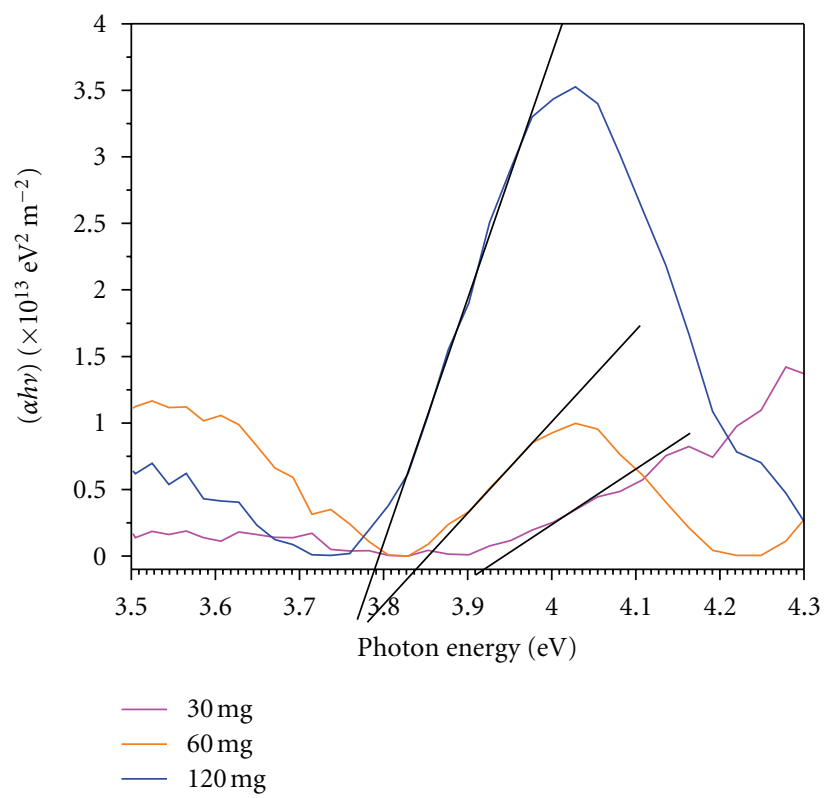

Figure 4: Optical band gap of PMMA thin film with different PMMA concentration.

3.84 , and $3.79 \mathrm{eV}$ for 30,60 , and $120 \mathrm{mg}$, respectively. It can be seen that as the PMMA concentration increased the $E_{g}$ decreased. The variation in optical band gap at different PMMA concentration might be due to optical scattering by the grain boundaries. The reduction in light absorption coefficient properties for thin film prepared at $120 \mathrm{mg}$ concentration might be due to the defects in the thin films which got higher as the growth along $c$-axis becomes lower at high concentration. The grain boundaries effect which scatters the light that is reduced is believed to be the factor of this phenomenon. These results are contradict with the values obtain by Ahmed and Švorčik et al. that are $4.6 \mathrm{eV}$ and $[8,19]$. Table 2 summarizes the optical properties of PMMA thin film at different concentration

$$
(\alpha h v)^{2}=A\left(h v-E_{g}\right)^{1 / 2}
$$

3.3. Surface Morphology. In order to investigate the influence of PMMA concentration on the morphology, the topography of the films was determined using AFM technique shown in Figure 5. The AFM images show that all films are uniform and there is no significant difference between all concentration. The average roughness, $R_{A}$ is $0.543 \mathrm{~nm}, 0.605 \mathrm{~nm}$, 


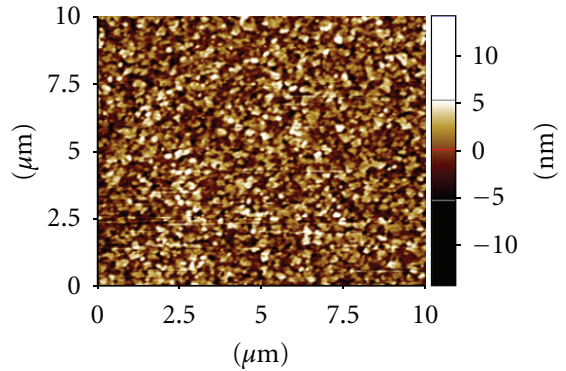

(a) $30 \mathrm{mg}$

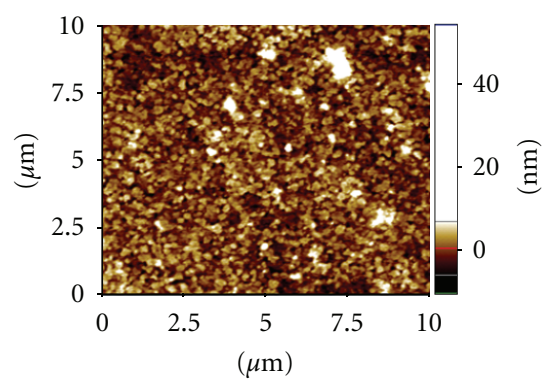

(b) $60 \mathrm{mg}$

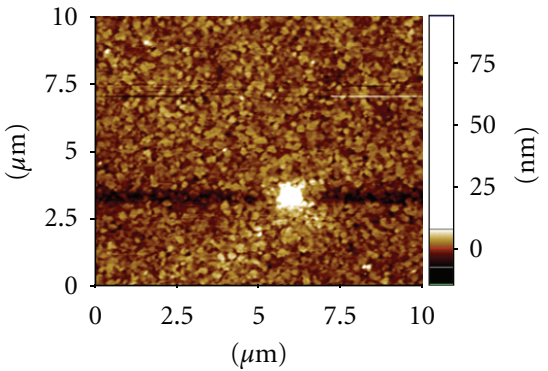

(c) $120 \mathrm{mg}$

FIGURE 5: Morphologies of PMMA thin film with different concentration.

TABle 2: Properties of PMMA thin film at different concentration.

\begin{tabular}{lcc}
\hline $\begin{array}{l}\text { PMMA concentration } \\
(\mathrm{mg})\end{array}$ & $\begin{array}{c}\text { Thickness } \\
(\mathrm{nm})\end{array}$ & $\begin{array}{c}\text { Optical band gap } \\
\text { energy }(\mathrm{eV})\end{array}$ \\
\hline 30 & 65.6 & 3.92 \\
60 & 102.7 & 3.84 \\
120 & 141.1 & 3.79 \\
\hline
\end{tabular}

and $0.712 \mathrm{~nm}$ for 30,60 , and $120 \mathrm{mg}$. The results show that the $R_{A}$ is increased when the concentration increased. This increasing in the surface roughness is due to the solution viscosity with the increment of PMMA concentration.

\section{Conclusion}

In summary, we have investigated the influence of PMMA concentration on dielectric, optical, and morphological properties of PMMA thin films. Dielectric properties of PMMA thin films have shown by varying the amount of PMMA concentration. The dielectric permittivity and dielectric loss are reduced as the concentration is increased. The optical properties of PMMA thin film show that all films are high as reported by other researcher. The optical band gap found to be increased with doping concentration. The morphology properties show that all films are uniform and the surface roughness is increased due to the increment in the solution viscosity.

\section{Acknowledgments}

Authors would like to acknowledge the Research Management Institute (RMI), UiTM Shah Alam, and Ministry of Higher Education (MOHE) Malaysia for the funding. Authors also would like to acknowledge NANO-Sci Tech Centre (NST), Institutes of Sciences UiTM Shah Alam for their AFM equipment.

\section{References}

[1] D. Dorranian, Z. Abedini, A. Hojabri, and M. Ghoranneviss, "Structural and optical characterization of PMMA surface treated in low power nitrogen and oxygen RF plasmas," Journal of Non-Oxide Glasses, vol. 1, pp. 217-229, 2009.
[2] H. M. Ahmed and S. A. B. Aziz, "Dielectric Properties of Commercial non-Polar Polymers," 2008.

[3] D. Knipp, P. Kumar, A. R. Völkel, and R. A. Street, "Influence of organic gate dielectrics on the performance of pentacene thin film transistors," Synthetic Metals, vol. 155, no. 3, pp. 485489, 2005.

[4] M. Mukherjee, B. Mukherjee, Y. Choi, K. Sim, J. Do, and S. Pyo, "Investigation of organic n-type field-effect transistor performance on the polymeric gate dielectrics," Synthetic Metals, vol. 160, no. 5-6, pp. 504-509, 2010.

[5] C. Feng, T. Mei, and X. Hu, "Influence of trapping states at the dielectric-dielectric interface on the stability of organic field-effect transistors with bilayer gate dielectric," Organic Electronics, vol. 12, no. 8, pp. 1304-1313, 2011.

[6] H. Wang, P. Xu, W. Zhong, L. Shen, and Q. Du, “Transparent poly(methyl methacrylate)/silica/zirconia nanocomposites with excellent thermal stabilities," Polymer Degradation and Stability, vol. 87, no. 2, pp. 319-327, 2005.

[7] H. M. Zidan and M. Abu-Elnader, "Structural and optical properties of pure PMMA and metal chloride-doped PMMA films," Physica B, vol. 355, no. 1-4, pp. 308-317, 2005.

[8] R. M. Ahmed, "Optical study on poly(methyl methacrylate)/poly(vinyl acetate) blends," International Journal of Photoenergy, vol. 2009, Article ID 150389, 9 pages, 2009.

[9] N. G. Semaltianos, "Spin-coated PMMA films," Microelectronics Journal, vol. 38, no. 6-7, pp. 754-761, 2007.

[10] X. Sun, X. Chen, X. Liu, and S. Qu, "Optical properties of poly(methyl methacrylate)-titania nanostructure thin films containing ellipsoid-shaped titania nanoparticles from ex-situ sol-gel method at low growth temperature," Applied Physics B, vol. 103, no. 2, pp. 391-398, 2011.

[11] T. S. Huang, Y. K. Su, and P. C. Wang, "Poly(methyl methacrylate) dielectric material applied in organic thin film transistors," Japanese Journal of Applied Physics, vol. 47, no. 4, pp. 3185-3188, 2008.

[12] I. Mejia and M. Estrada, "Characterization of Polymethyl Methacrylate (PMMA) layers for OTFTs gate dielectric," in Proceedings of the 6th International Caribbean Conference on Devices, Circuits and Systems, pp. 375-377, April 2006.

[13] V. Bornand, C. Vacher, A. Collet, and P. Papet, "Interest of binary PMMA/P(VDF-TrFE) blend thin films," Materials Chemistry and Physics, vol. 117, no. 1, pp. 169-172, 2009.

[14] A. Rana, O. P. Thakur, and V. Kumar, "Effect of Gd3+ substitution on dielectric properties of nano cobalt ferrite," Materials Letters, vol. 65, no. 19-20, pp. 3191-3192, 2011.

[15] E. A. Stefanescu, X. Tan, Z. Lin, N. Bowler, and M. R. Kessler, "Multifunctional PMMA-Ceramic composites as structural dielectrics," Polymer, vol. 51, no. 24, pp. 5823-5832, 2010. 
[16] Q. Meng, W. Li, Y. Zheng, and Z. Zhang, "Effect of poly(methyl methacrylate) addition on the dielectric and energy storage properties of poly(vinylidene fluoride)," Journal of Applied Polymer Science, vol. 116, no. 5, pp. 2674-2684, 2010.

[17] S. Lavina, E. Negro, G. Pace et al., "Dielectric low-k composite films based on PMMA, PVC and methylsiloxane-silica: synthesis, characterization and electrical properties," Journal of Non-Crystalline Solids, vol. 353, no. 30-31, pp. 2878-2888, 2007.

[18] Z.-M. Dang, J.-K. Yuan, J.-W. Zha, T. Zhou, S.-T. Li, and G.-H. Hu, "Fundamentals, processes and applications of high-permittivity polymer-matrix composites," Progress in Materials Science, vol. 57, no. 4, pp. 660-723, 2012.

[19] V. Švorčík, T. Podgrabinski, J. Náhlik, V. Rybka, and V. Hnatowicz, "Dielectric properties of doped polymethylmethacrylate," Materials Letters, vol. 59, no. 2-3, pp. 341-344, 2005. 

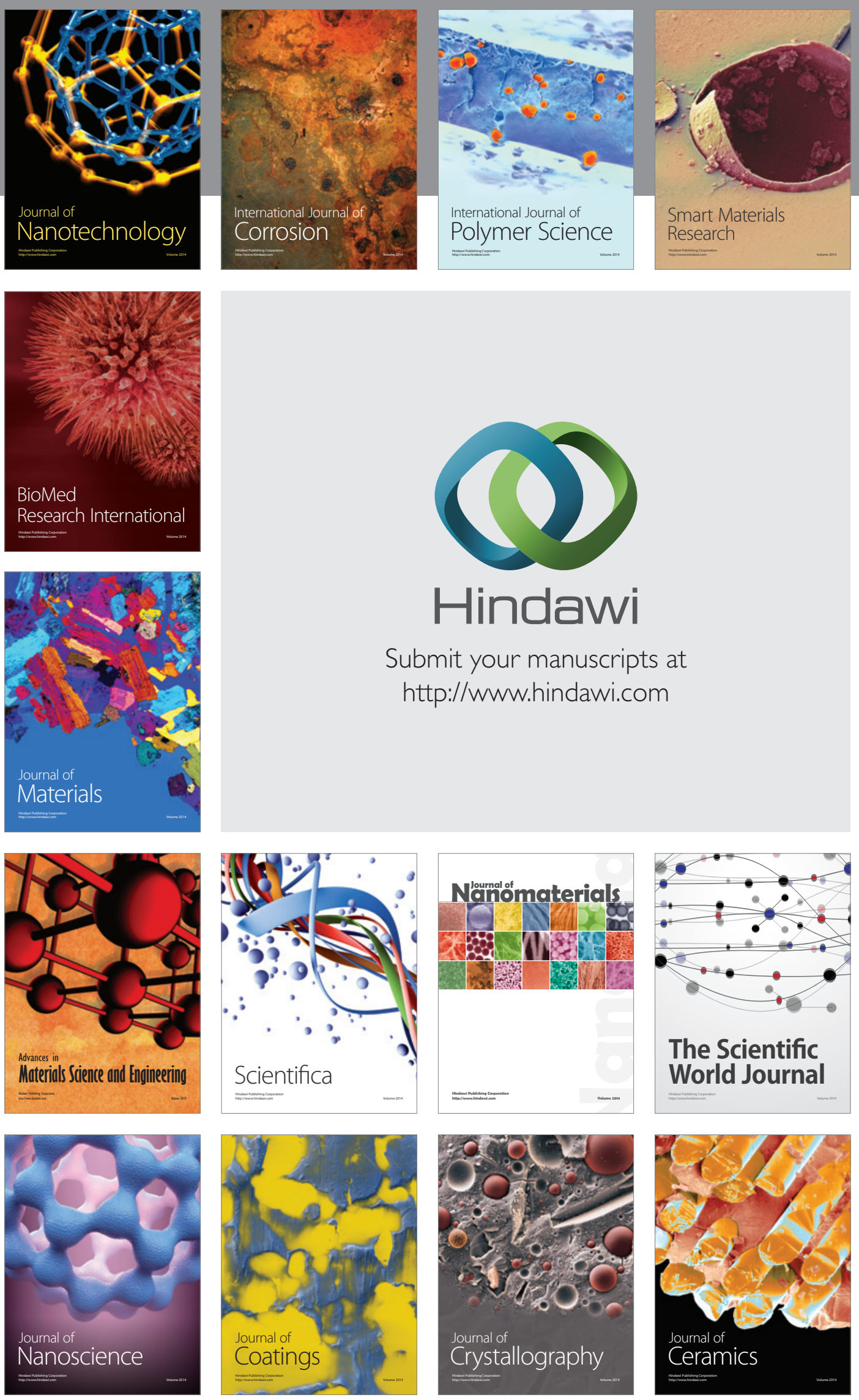

The Scientific World Journal

Submit your manuscripts at

http://www.hindawi.com

\section{World Journal}

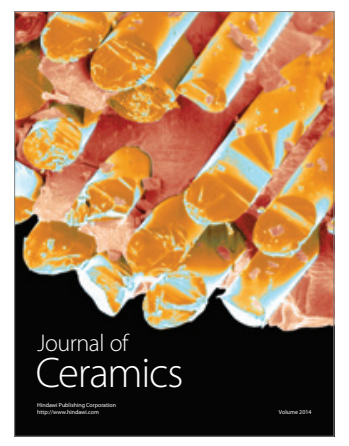

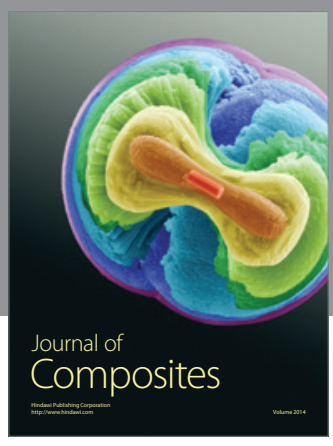
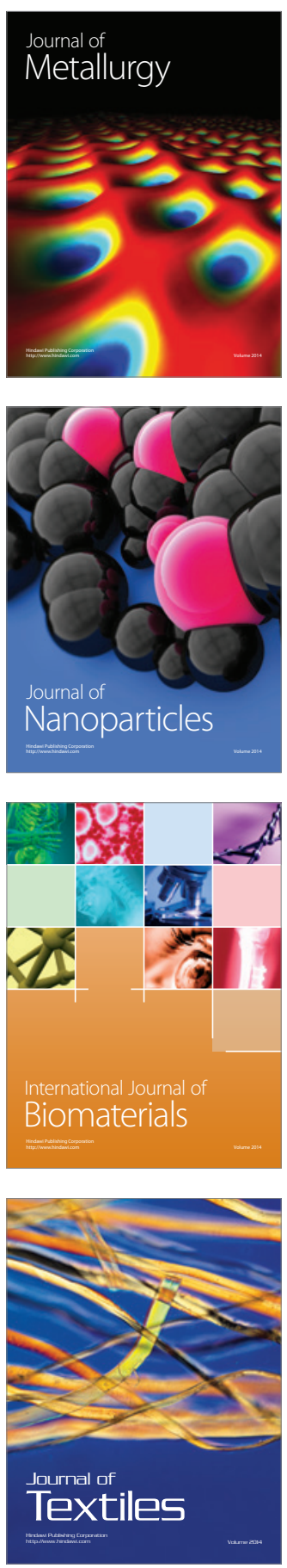